\title{
ENSAYOS CLIINICOS Y SALUD PÚBLICA EN EL PERÚ: RECONCILIANDO UN INNECESARIO DIVORCIO
}

\author{
CLINICAL TRIALS AND PUBLIC HEALTH IN PERU: RECONCILING AN UNNECESSARY DIVORCE
}

Alonso Soto ${ }^{1,2, a}$

La medicina basada en evidencias constituye uno de los pilares actuales para las decisiones sobre intervenciones sanitarias tanto a nivel individual como a nivel colectivo. En sistemas de salud con escaso financiamiento, las necesidades usualmente rebasan el presupuesto disponible por lo que la priorización de actividades constituye un eje fundamental para la toma de decisiones a fin de emplear correctamente los escasos recursos disponibles. La priorización de intervenciones se basa en criterios de eficiencia los que a su vez dependen de la efectividad y el costo de las intervenciones. La implementación de políticas sanitarias depende no solo de contar con el presupuesto necesario, sino además de contar con evidencia sólida sobre la efectividad de la intervención planeada en un contexto específico.

Ante una pregunta relevante para la salud pública, la primera aproximación es conocer si existe ya una respuesta; para ello la revisión sistemática de literatura ofrece en muchos casos una base sobre la cual implementar decisiones programáticas. Sin embargo, en muchas ocasiones no existen respuestas concretas o acordes al escenario sanitario específico. En tales situaciones las decisiones suelen ser basadas en una determinada coyuntura o criterio individual, lo que puede llevar a aplicar medidas tan costosas como inútiles. Es en estas circunstancias en que los ensayos clínicos representan la mejor evidencia disponible para determinar la eficacia de una posible intervención. Un ensayo clínico es un estudio experimental y planeado en seres humanos (o comunidades) destinado a evaluar una intervención específica. Su ámbito incluye casi cualquier intervención en salud en la que exista incertidumbre sobre su efectividad. Esta intervención puede consistir en implementar un programa educativo, mejorar el diagnóstico de una condición, evaluar el impacto de la participación comunitaria, racionalizar la prescripción de antibióticos, entre otras muchas intervenciones posibles más allá de la mera evaluación de nuevas drogas. Desde la perspectiva de Salud Pública, resultan de creciente importancia los ensayos clínicos pragmáticos, es decir aquellos realizados bajo condiciones lo más cercanas a la práctica habitual ${ }^{\left({ }^{1}\right)} \mathrm{y}$ los ensayos clínicos por conglomerados (cluster) en los cuales la aplicación de la intervención se realiza a nivel de grupos de participantes (un centro de salud, un grupo de pacientes atendidos por un equipo de salud, etc.) ${ }^{(2)}$.

El origen de los ensayos clínicos está estrechamente relacionado a la búsqueda de intervenciones eficaces para problemas de Salud Pública y el primer ensayo clínico reconocido como tal consistió en la evaluación de la estreptomicina para el tratamiento de la tuberculosis ${ }^{(3)}$, estudio en el que la colaboración entre los gobiernos y la industria farmacéutica logró una respuesta adecuada frente a un problema relevante. El tiempo y el interés en generar nuevas drogas, habitualmente destinadas a ser usadas en países desarrollados, han llevado a una explosión de ensayos clínicos destinados a la evaluación de nuevas moléculas, habiéndose generado un divorcio entre los ensayos clínicos necesarios para responder a preguntas importantes para la salud pública de nuestro país y los que finalmente se efectúan. Ello ha llevado a una percepción equivocada sobre los ensayos clínicos en el Perú, entendiéndose generalmente como tales solo a los ensayos aleatorizados centrados en la evaluación de nuevas drogas. Esto es debido a que en el Perú la mayoría de los ensayos clínicos realizados son lo que se conoce coloquialmente como "enlatados", es decir ensayos clínicos multicéntricos diseñados por compañías farmacéuticas transnacionales, en los que el rol de los llamados "investigadores principales" se centra en el reclutamiento de pacientes sin participación alguna en el diseño, análisis o elaboración posterior de las subsiguientes publicaciones. Estos ensayos se realizan crecientemente en países en vías de desarrollo debido en primer lugar a regulaciones menos estrictas

\footnotetext{
Hospital Nacional Hipólito Unanue. Lima, Perú.

General Epidemiology and Disease Control Unit, Institute of Tropical Medicine. Antwerp, Belgium.

Médico internista magister en Estadística Aplicada

Recibido: 24-10-12 Aprobado: 31-10-12
} 
y en segundo lugar a que en países desarrollados, el empoderamiento de los pacientes y su creciente conocimiento e involucramiento en las decisiones terapéuticas hacen menos probable que estos se arriesguen a recibir nuevos tratamientos, particularmente si el sistema de salud les permite el acceso irrestricto al tratamiento convencional basado en la mejor evidencia disponible.

Es preciso entonces reconciliar el divorcio entre la Salud Pública y los ensayos clínicos dada la relevancia de estos últimos para la toma de decisiones. El abordaje científico frente a nuestros problemas de salud resultará finalmente en un gasto público eficiente con una mayor probabilidad de tener un impacto real. La identificación de las prioridades en investigación nacionales ha sido un importante primer paso; identificadas las prioridades, el siguiente paso y el reto a afrontar es la evaluación científica en aquellos vacíos del conocimiento para decidir la mejor intervención posible. La realización de ensayos que evalúen dichas intervenciones con un enfoque pragmático acorde a nuestra realidad suele considerarse sin embargo casi una utopía. La demostración de la eficacia de una intervención depende generalmente de lograr reclutar un gran número de participantes, lo que implica la necesidad de contar con recursos económicos, humanos y logísticos que suelen sobrepasar las buenas intenciones de los investigadores locales. El reto es enorme, pero la necesidad también. El acercamiento entre la Organización Mundial de la Salud y la industria farmacéutica ha permitido la generación de ensayos clínicos destinados a optimizar el tratamiento de la tuberculosis multidrogorresistente $y$, como con la estreptomicina en el siglo pasado, es una muestra de la factibilidad de reconciliar la Salud Pública con el desarrollo de ensayos clínicos. A nivel local, algunas experiencias en malaria ${ }^{(4)}$, infección por virus del papiloma humano ${ }^{(5)}$ y sistemas de información en tuberculosis (6) demuestran que sí es posible lograr realizar ensayos clínicos acordes a preguntas relevantes para nuestro país. Sin embargo es evidente la necesidad de fortalecer la investigación destinada a conocer las mejores soluciones de los problemas de salud. La responsabilidad es conjunta y requiere la intervención de todos los componentes del sistema de salud y las instituciones académicas.

Una primera necesidad es la generación una masa crítica de investigadores capacitados para llevar a cabo estos ensayos. La capacitación debe incluir aspectos teóricos pero también entrenamiento práctico en la elaboración de protocolos, monitoreo y aspectos logísticos, por ejemplo a través de la colaboración de la industria farmacéutica. Evitar la fuga de cerebros a través de incentivos apropiados es crucial para evitar que esta formación de recursos humanos sea inútil. Un siguiente punto es el financiamiento de los estudios basados en las prioridades nacionales. Ello puede partir de los presupuestos regionales para investigación (los que actualmente son subutilizados), a través de los fondos provenientes de la actividad minera, de la cooperación internacional o la propia industria farmacéutica. Estos fondos podrían canalizarse a través de convocatorias que involucren la participación de universidades y otras instituciones dedicadas a la investigación. Las Universidades en particular deben pasar de ser centros de formación teórica o clínica a ser núcleos generadores de investigación. Adicionalmente, es importante que los resultados de las investigaciones sean realmente utilizados para la toma eficiente de decisiones basadas en la evidencia generada; de no ser así, la investigación corre el riesgo de convertirse en un gasto inútil.

En suma, los ensayos clínicos son una fuente de evidencias crucial para la toma de decisiones e impulsar su desarrollo es una necesidad impostergable para la salud en el Perú. La transición hacia una Salud Pública basada en evidencias puede ser difícil, pero es hora de asumir nuestra responsabilidad en la generación de conocimiento. Impulsar la ciencia y tecnología es finalmente el reto y la vía para lograr un desarrollo sostenible como nación.

\section{REFERENCIAS BIBLIOGRÁFICAS}

1. Brass EP. The gap between clinical trials and clinical practice: the use of pragmatic clinical trials to inform regulatory decision making. Clin Pharmacol Ther. 2010;87(3):351-5.

2. Hayes RJ, Moulton L. Cluster Randomised Trials. Boca Raton: Chapman \& Hall; 2009.

3. MRC Streptomycin in Tuberculosis Trials Committee. Streptomycin treatment of pulmonary tuberculosis.
BMJ. 1948;ii:769-83.

4. de Oliveira AM, Chavez J, de Leon GP, Durand S, Arrospide N, Roberts J, et al. Efficacy and effectiveness of mefloquine and artesunate combination therapy for uncomplicated Plasmodium falciparum malaria in the Peruvian Amazon. Am J Trop Med Hyg. 2011;85(3):573-8.

5. Brown B, Blas M, Cabral A, Carcamo C, Gravitt P, Halsey N. Randomized trial of HPV4 vaccine assessing the response to
HPV4 vaccine in two schedules among Peruvian female sex workers. Vaccine. 2012;30(13):2309-14.

6. Blaya JA, Shin SS, Yale G, Suarez C, Asencios L, Contreras C, et al. Electronic laboratory system reduces errors in National Tuberculosis Program: a cluster randomized controlled trial. Int J Tuberc Lung Dis. 2010;14(8):1009-15. 